This is an Accepted Manuscript of an article published by Taylor \& Francis in Design for Health on 16/04/19, available online:

https://www.tandfonline.com/doi/full/10.1080/24735132.2019.1577524 


\section{A gift from experience: Co-production and co-design in stroke and self-management}

Stefan Tino Kulnik (corresponding author)

Faculty of Health, Social Care and Education, Kingston University and St George's, University of London, London, United Kingdom

$6^{\text {th }}$ Floor Hunter Wing, Desk 18 - Bay 18, St George's Campus, Cranmer Terrace, London SW17 0RE, United Kingdom

Phone +44(0)20 87252266

Mobile +44 (0)7758369472

Emails.t.kulnik@sgul.kingston.ac.uk

ORCiD 0000-0001-5419-6713

Heide Pöstges

Bridges Self-Management Limited, London, United Kingdom

Faculty of Health, Social Care and Education, Kingston University and St George's, University of London, London, United Kingdom

Rosemary Townsend

Dyscover Limited, Surrey, United Kingdom

Paul Micklethwaite 
Department of 3D Design, The Design School, Kingston School of Art, Kingston

University, London, United Kingdom

\section{Fiona Jones}

Faculty of Health, Social Care and Education, Kingston University and St George's, University of London, London, United Kingdom

Bridges Self-Management Limited, London, United Kingdom

There is increasing emphasis on co-production and co-design of healthcare, for example the co-design of resources to support people with stroke in selfmanagement. Limited accessibility of materials for people with aphasia (difficulty producing and/or understanding language) is a topical issue. In this paper we describe our experiences of working with people with stroke and rehabilitation professionals to co-design a resource (book) for stroke selfmanagement support, incorporating accessibility for people with aphasia. In the highly medicalised field of stroke care, rigour is mainly informed by biomedical experimental research paradigms. Interpretations of value are often grounded in assumptions of biological and social norm. In contrast, our work was guided by 'designerly' conceptualizations of rigour and value. We considered design 'things' (objects/artefacts) versus 'Things' (a forum for people to come together); the book as a boundary object; reciprocity throughout the co-design process; and a pragmatic premise of participatory design. Stroke survivors gifted their stories and experiences to fill the pages of the book. In reflecting on our work, we have made transparent how we 'do' co-design. We have demonstrated rigour through local accountability. There is value in the book's ability to connect people with stroke and support an encouraging and empowering self-management dialogue.

Keywords: aphasia, co-design, reciprocity, self-management, stroke 


\section{Introduction}

Over the past decade, a new way of working has entered the field of stroke care and rehabilitation, which incorporates a focus on patient self-management and the provision of self-management support (ISWP 2016, 27-28; Jones, Riazi, and Norris 2013; Jones 2006). Stroke services and practitioners who work according to a self-management approach not only recognize the experience of people with stroke in managing their condition and their life after stroke; but they place emphasis on valuing and fostering this person-held expertise. Stroke services that seek to realize this way of working will need to design their processes and products accordingly, and co-production and codesign can play a central part in this (Jones, Pöstges, and Brimicombe 2016).

This relatively recent entry of self-management, co-production and co-design approaches to the field of stroke care and rehabilitation has taken place within a wider, macro-level shift across health and social care practice and research over the past two decades. In the United Kingdom (UK), there has been a governmental drive to increase involvement of service users in the delivery of health and social care services, to ensure the voice of patients and the public is sought and heard in the design and implementation of improvement strategies. Often referred to as Patient and Public Involvement (PPI), this approach encourages - or even requires - engagement with service users in the planning and improvement of publicly funded services (SCIE 2015). The same has been introduced to the field of research, where the involvement of people with health conditions and their caregivers at all stages of the research process is now a common requirement of funding agencies. The premise is that this will improve the research at all levels, from conception and design to dissemination, implementation and impact (INVOLVE 2013). In practice, however, 'involvement' may be minimal and tokenistic, or even disingenuous; it may be conducted in a more traditional and 
formulaic manner - often well-intentioned but restricted by researchers' limited knowledge and skills; or it may take on very creative and novel forms that attempt to transform the relationship between 'citizens' and researchers.

In the world of industry and design, a similar shift has taken place over the past 30 years, with the field moving from designing 'for' people to designing 'with' and 'by' people, described as a development from designing to co-designing. At a macro-level, this illustrates a re-focus of what is considered important, which may reflect a subtle cultural evolution in at least some strata of our globalized capitalist societies:

Success is no longer defined primarily by monetary value such as sales in the marketplace. Beyond monetary value, we now see experience value, the objective of which is to meet the wants and needs of people, as well as social value, the objective of which is to be able to deliver on more sustainable and convivial ways of living. (Sanders and Stappers 2014, 30)

A further parallel to this is evident in high-level international health policy, for example in the World Health Organization's report on health literacy (WHO 2013), which frames a future of 'health citizenship' that

... requires a combination of personal and social responsibility from individuals, but even more so it requires the institutions of society to promote choice, empowerment, self-management, responsiveness and participation in health and well-being. (WHO 2013, 31)

Within this framework, the importance of health literacy is also emphasized, and it is the role of 'health literacy-friendly organizations' to involve the populations served (i.e. users) in the design, implementation and evaluation of health information (WHO 2013, 31-34). This message brings together the disciplines of healthcare and design at the highest policy level, in a strategic direction that 
... seeks to empower individuals to make effective decisions about their own health, becoming articulate and empowered co-producers of health services. Communities are enabled to become actively engaged in co-producing healthy environments, providing care services in partnership with the health sector and contributing to healthy public policy. (WHO 2015, 21)

Such policy implies an idealized notion of co-production that creates a moral obligation for all individuals and institutions to actively engage and contribute their share to the production of health services. Healthcare practitioners can, however, face ethical dilemmas in practice when users of services are either unable or reluctant to take on a more active role (van de Bovenkamp 2017).

\section{Design of printed/visual materials for people with stroke}

Against this background, there is a need to reflect on the application of co-production and co-design in the field of stroke care and rehabilitation, for example with respect to the design of printed/visual materials to support self-management. While we acknowledge the wider literature defining 'co-production' and 'co-design' (e.g. SCIE 2015 and others), in our use of the terms for the purpose of this paper we think of 'coproduction' as the ethos (or the methodology) that underpins our approach, and 'codesign' as the practice (or the method) through which it is realized.

The provision of information is an important aspect of stroke care and rehabilitation. This has been highlighted in the current UK National Clinical Guideline for Stroke (ISWP 2016, 17), the Sentinel Stroke National Audit Programme (ISWP 2015, 7), and the National Institute for Health and Care Excellence stroke rehabilitation guidelines (NICE 2013, 19-20). The strong focus on patient education has derived historically from a practice model that appreciates professional expertise more than the patient perspective and puts the responsibility for holding and providing knowledge 
with professionals. This links with Fricker's (2007) concept of epistemic injustice, in which the testimony of one speaker (e.g. a patient's) is afforded less credibility, and their relative powerlessness creates a structural disadvantage in articulating their social experiences. This hinders collaborative working as it leaves little opportunity for people with stroke to share their views with professionals, learn from each other's real-life experiences of living with stroke, and influence access to information. In practice, therefore, efforts to live up to an idealized ethos of co-production are commonly confined by unidirectional interactions and flow of information, directed from expert professionals towards patients and their family members. This pattern is evident not only in the provision of healthcare services, but also in research practices in medicine and rehabilitation.

The best ways of information giving in this context are unknown (Forster et al. 2012), but printed/visual materials are commonly used tools to support the process. Examples seen in hospital wards, rehabilitation units, and outpatient waiting areas range from materials that are produced in high quality print, to basic one-page sheets of paper with simply typeset information, or lesser-quality photocopies of information materials that cannot be restocked. The content often presents factual medical and clinical information ('textbook knowledge') as well as practical information, contact details and signposting to various services. Tightly resourced clinical services often rely on ad hoc, 'home-made' information materials, which are rarely produced within a developed, conceptual design framework. While professionally produced materials are available to clinical services - often supplied by charitable and voluntary sector organizations - , the application of dedicated co-design approaches in the development of these materials is less common. Unidirectional flow of information, limited accessibility, and sometimes reduced willingness of individuals to engage more actively in knowledge sharing, reveal 
unequal distributions of power between stroke rehabilitation practitioners and stroke survivors. This raises ethical and practical questions about how to best co-design and use self-management materials that facilitate mutual relationships.

\section{Purpose}

In this paper, we use the concept of reciprocity as a lens to reflect on the practicalities of co-production and co-design in stroke self-management. We draw on Mauss' (2000) notion of the 'gift'. Accordingly, a gift usually comes with an obligation to give something in return. In this sense, gift exchanges can create social bonding and reinforce norms in terms of moral obligations. In the context of stroke rehabilitation and self-management, gifts can include taking individual and social responsibility and providing personal insights and knowledge to enable shared decision-making.

The extent to which people with stroke actively engage in this 'gift-giving' process through sharing and using their own knowledge and skills can vary. Our aim is to demonstrate how using reciprocity as a focal point throughout and beyond the codesign process may elucidate conceptual and practical tensions between theoretical, sometimes idealized perspectives of participatory design, and the realities and pragmatism of the actual process of designing a co-produced book.

Following a 'research through practice' approach (Archer 1995), we drew on our own experiences of working with people with stroke and stroke rehabilitation practitioners, to reflect on the process of designing a bespoke book that is given to people with stroke as part of their self-management support. As one concrete example, we discuss how we addressed the aspect of accessibility of the book to people with aphasia (i.e. difficulty producing and/or understanding language in spoken and/or written form). In reflecting on our personal learning points, we intend to provide an 
account that may inform future work in this area and benefit others who operate in the field of stroke self-management.

\section{Why a book?}

A book for supporting people with stroke in their self-management was first created by the senior author $(\mathrm{FJ})$ in 2005 , as part of her work adapting a self-management approach to the field of stroke rehabilitation (Jones, Pöstges, and Brimicombe 2016; Jones 2004). This work has resulted in the development of 'Bridges', an approach to person-centred self-management support in stroke rehabilitation. Bridges provides an overarching framework within which teams can implement and sustain enhanced self-management support. Since 2013, Bridges has operated as a non-profit organisation, pursuing a social mission through the people who contribute to its development (people with stroke, their family members and friends, rehabilitation professionals, members of the Bridges team and its affiliates). As part of the work, Bridges produces self-management resources and tools for patients, family members and professionals, including 'the book'.

The decision to produce a book is grounded in its purpose and function within the self-management approach. These are in turn informed by several methodological considerations, which provide the point of departure for the design process. Briefly, the Bridges approach realizes self-management support through supporting rehabilitation practitioners (therapists, nurses, doctors, support workers) to work more collaboratively with stroke survivors and their family members. There is an emphasis on using language that helps to get to the heart of what is most important to people quicker, and shaping interactions in a way that will foster self-management principles such as goalsetting, problem solving, taking action and self-discovery. Within this self-management dialogue, the book provides a focal point and can act as a conversation starter. It 
presents stroke survivors' stories, accounts of their experiences and the impact of stroke, and examples and suggestions of practical 'tips' and ways they manage life after stroke. Through the pages of the book, these stories - words and images - give stroke survivors an opportunity to connect with others who are in a similar situation, which supports self-management processes of peer support, peer learning, social comparison and modelling. In addition, the book also contains space for stroke survivors, their family members, and rehabilitation professionals to reflect on and note down goals, hopes for the future, action plans, and reflections on action, to support and facilitate the ongoing self-management conversations (Jones, Pöstges, and Brimicombe 2016).

\section{The book as a boundary object}

We have reflected on how best to conceptualize the multiple functions and flexible application of the book. The agile form taken during the design process of the book is possible because it simultaneously exists as a tangible structure built on defined values whilst having fluidity to be what it needs to be for each recipient and provider. First described by Star and Griesemer (1989), the concept of both Bridges and the book as a boundary object can provide a helpful explanatory model about how consensus was arrived at as an object in the material sense, and one which facilitates new levels of understanding between stroke survivors and healthcare professionals.

As a boundary object the book clearly belongs to different social worlds, which can create both conflict and concern, but also helps to 'bridge' the gap between different groups: the healthcare professional who perceives their patient is 'not ready' for the book and holds onto it; the patient who states 'there is no right time to give it out, and let us be the judge'; and the family member who uses the book to 'get ideas and inspiration' from other family members. In training workshops for rehabilitation teams, the book can serve to spark discussion, sometimes manifesting as concern or conflict 
about how it fits with professionals' own social worlds. But we have witnessed sharp changes in views and blurring of attitudes as healthcare professionals read the narratives of stroke patients and digest feedback from other staff about their successes with the book.

The dynamic nature of a boundary object was further expanded by Star in 2010. In addition to interpretive flexibility in the use and understanding of the object, Star highlighted that the material and organizational structures and scale within which a boundary object exists are also pertinent. Together, these aspects shape how a boundary object may positively enable different groups to work together with little or no consensus. In the design process the nature of co-operation and the gradual tailoring of content resides somewhere between the stroke survivor contributors, the Bridges team, and further design contributors. The latter are professional graphic designers who are provided with the content and design vision for the book to craft the actual design. In training workshops, on the hospital ward, at home, the book as an object takes on different meanings and use. As a community with a common set of person-centred values we are comfortable with the notion that absolute consensus can never be reached and can be adapted to local needs as well as the constraints placed upon it. But the book gradually achieves a sense of identity, which feels comfortable to different groups in different social worlds.

The first edition of the Bridges book started as an idea conceptualized by FJ and developed in conjunction with professionals, stroke survivors and family members. The process was more rigid, following a traditional method of content generation through interviews, and extraction by FJ working together with a designer. A prototype was shown to stroke survivors, including a group of people with communication difficulty, 
and modifications were made as a result of their feedback. Over the years, the book has undergone small modifications, updates and additions, all with the involvement and participation of stroke survivors. The accumulation of 10 years of feedback from stroke survivors and professionals necessitated a more radical review from first principles, with the aim of co-designing a new edition using a more thorough and elaborate participatory approach.

\section{How we co-designed the book}

We consider that our self-management approach links with two value strategies that guide participatory co-design, as described by Bjögvinsson et al. (2012, 103): Firstly, the social and rational idea of democracy, with the imperative to create conditions that enable proper and legitimate user participation. This is described as design 'Things', i.e. a forum for people to come together and enact and resolve controversies. And secondly, the importance of making participants' tacit knowledge come into play (not just their formal and explicit competencies) - to benefit from their practical and diverse skills in the making of 'things' as objects and artefacts. There is a strong parallel to our coproduction ethos and practice of self-management.

The process of design and development - the project as the 'Thing', i.e. the alignment of design activity (Bjögvinsson et al. 2012) - by necessity takes place within resource parameters of time, monies, technical and creative know-how of the design team, and, in the context of participatory co-design, the availability and capacity of codesign participants, e.g. people with stroke. There is therefore a pragmatism that underlies the process. In this respect we share the notion of a pragmatic and a moral premise of participatory design. As Holmlid $(2009,109)$ describes, the pragmatic premise states that direct inclusion of users' input will increase the probability of a 
design outcome that is successful. The moral premise is that users have a right, even an obligation, to be directly involved in the process of development. However, in line with Duysburgh and Slegers (2015), we feel a strong commitment to shifting the focus from users' obligation to an obligation of reciprocity for us as researchers and designers to give something back for receiving the contributors' invaluable 'gift' of their personal experience of everyday life after stroke. In doing so, we intend to ensure that involvement is of mutual benefit. We learned, for instance, that offering gift vouchers as reimbursement for contributors' time was often considered less important; but that contributors valued being listened to and supporting positive change in healthcare.

In the following, we describe our research method, and practical and pragmatic steps in co-designing the new book, to elucidate how the practice of co-designing was operationalized for this project. We identify opportunities to reciprocate for contributors' help in achieving a better design outcome. Figure 1 describes the sequential steps in the book development; the extent to which touch points with people with stroke included co-design activities (i.e. the 'level' of collaboration); and the nature of co-design activities according to the framework for organising tools and techniques of participatory design proposed by Sanders, Brandt and Binder (2010).

\section{FIGURE 1 ABOUT HERE}

Our activities drew on various qualitative methods, using supportive communication strategies, such as meeting at a venue and creating an environment where participants felt comfortable; giving participants time to formulate their accounts; not pre-empting participants' words; repeating back participants' words, to check and confirm our 
understanding and participants' intended meaning; and making use of gestures, writing and visual communication aids.

We used images to supplement and illustrate stroke survivors' accounts in the book. These are photographs taken at the time of the interview, and/or pictures provided by participants themselves. In the book, we aimed to include portraiture-type photographs (putting the person's image with their name and words), as well as images that represent the person in what they like, what they like doing, what they are good at, and what makes them the person they are.

Step three (content generation - listening to stroke survivors' stories) reflects the core principle to this method, which is to bring together different perspectives of people with stroke, placing value on the authenticity of content that is generated by people who speak from experience. This content is entrusted (gifted) to the Bridges team, who conducted the work of content extraction and synthesis.

As a research and design team, we felt privileged to work with the raw interview data and start the process of representing each person's narrative. We sought to ensure reciprocity by being mindful of the need to maintain the essence and individual nature of each experience, whilst aligning the content with an overall theme of supporting selfmanagement. The process was iterative, moving forward towards a common goal, as well as responding to any queries of concerns or edits requested by contributors. In doing so, we aimed to strike a balance between working to a project timeline on the one hand, and maintaining a continuous feedback loop to contributors on the other, to enable double-checking and reassurance, and to provide options for participants to veto. Another balance to strike related to maintaining momentum, while also anticipating that there would be unexpected, serendipitous developments, and allowing these to unfold and benefit the process. 
In the following, we give an example of how our iterative approach shaped one particular design feature we sought to incorporate in the new book, namely the aspect of increased accessibility to people with communication difficulty due to stroke (aphasia), and the considerations and decisions that resulted in the eventual co-design.

\section{Negotiating the process: Increasing the book's accessibility for people with aphasia}

Accessibility of the book for people with aphasia was an important consideration, given that approximately one third of stroke survivors can experience difficulty producing and/or understanding language in spoken and/or written form (Engelter et al. 2006). Recent figures from the UK show that approximately half of stroke survivors require communication assessment by a speech and language therapist during the first weeks following stroke (ISWP 2017, 65). Accessibility of written materials for stroke survivors with aphasia is therefore a pertinent issue.

It is acknowledged that individuals with aphasia are often excluded from strokerelevant information sources, support services and research, and there has been a call to increase accessibility for those with aphasia (Wray, Clark, and Forster 2017; Cadilhac et al. 2016). For example, the UK National Institute for Health Research (NIHR) and the charity Stroke Association have recently produced a toolkit for designing printed/visual research-related materials that are more accessible to people with aphasia (Pearl and Cruice 2017; NIHR CRN Stroke 2014). Similarly, evidence-based guiding principles for 'aphasia friendly' written health information have been described by researchers at University of Queensland, Australia. Examples of formal criteria that are generally associated with greater accessibility are: sans serif font of minimum 14-point size; 1.5 or double line spacing; blank space around sections of text; use of graphics to support 
the text; presenting numbers as both figures and words; using bold font to emphasize key words; using short sentences and bullet points; etc. (Rose et al. 2012, 2011). With respect to the difficulty of text, a general recommendation for accessible materials suggests readability equivalent to 5-6 years of formal education, for example using the Flesch-Kincaid grade level readability score (Worrall et al. 2007; Kincaid et al. 1975; Flesch 1949).

While these recommendations provide useful design guidance, authors also consistently make the point that these types of criteria should not be applied in a rigid manner. For example, not all people with aphasia welcome exaggerated simplification of content. Rather, it is important that people with aphasia are involved in the development and design of materials; and no one set of principles will meet the needs and preferences of all people with aphasia (Worrall et al. 2017, Rose et al. 2012). Designing for accessibility is therefore not conceptualized as following a prescriptive and formulaic recipe, but as an interaction of the product or service with the user in terms of 'fit' (Worrall et al. 2007), which echoes the premise of user-centred and userled design, and the importance of context and contextualization in the design and provision of self-management support. Accordingly, our book evolved against the backdrop of recommended formal criteria but not led by rules, being open to possibilities and the way people envisaged the look and feel of the book.

To illustrate this, sample pages of the book are shown in Figures 2, 3 and 4. Many sections of the book incorporate recommended aphasia friendly design, such as sans serif font, larger font size, bold font for emphasis, little text, space around text, and use of images, as shown in Figure 2. However, in catering to a wide audience of people with stroke, and not exclusively to people with aphasia, we were faced with two challenges: Firstly, to as much as possible include the information and messages that 
co-design contributors suggested in steps one and two of the design process; and secondly, to avoid loss of content and general appeal of the book through oversimplification.

\section{FIGURE 2 ABOUT HERE}

In addition to including more content about living and managing with aphasia, codesign contributors suggested that the new book would benefit from stories about people who have lived with stroke for a long time and younger stroke survivors; stories about returning to work after stroke; and content around dealing with tiredness and low mood. Conveying content in written/printed format requires page space and volume. We therefore needed to balance aphasia friendly format with aspects of purpose and also usability (size, weight and cost). In many of the book sections we therefore followed a more conventional text-based format with good readability, as in the example in Figure 3, which has a Flesch Reading Ease score of 74 (fairly easy) and a Flesch-Kincaid grade level of 5.4. The overall Flesch Reading Ease score for the entire book is 76.3 (fairly easy) with a Flesch-Kincaid grade level of 5.9.

\section{FIGURE 3 ABOUT HERE}

In contrast to these more conventionally designed sections, contributors suggested featuring their stories as people living with aphasia using very sparse text and mainly their own words, together with images (photographs and newly designed images) that convey the person's communication style and ways of managing with aphasia. For example, Figure 4a shows John using an App to supplement his speech. The page in 
Figure $4 \mathrm{~b}$ was designed in reference to Deena keeping information about her biography and current life situation stored on a tablet device, which she would show to others to support her spoken language. These design decisions also represent - and in a small way re-create - the 'scene' and conversation style during step three (content generation) with John, Deena, and Bridges team members.

\section{FIGURE 4 ABOUT HERE}

To juxtapose our evolving, iterative and pragmatic co-design for accessibility with a more formulaic approach, Figure 5 shows an example from the NIHR toolkit for stroke researchers (NIHR CRN Stroke 2014), which provides templates for patient-facing research documents and a bank of bespoke images, to assist researchers in designing accessible materials (Pearl and Cruice 2017). While this approach provides a good 'fit' in terms of functionality and practicality, in juxtaposition it also emphasizes the more personalized quality, look and feel, of the content coming through the pages of the Bridges book.

FIGURE 5 ABOUT HERE

\section{After the co-design}

\section{A gift that keeps giving}

We have reflected on how we supported the generation of a reciprocity loop that begins with contributors' gifts of experience and requires further joint efforts to ensure that these gifts are accessible to the intended recipients. We have learnt that giving and 
receiving the gift of insight from people with stroke is an ongoing process, since the book sparks further developments, interactions, discussions, and actions. In line with the argument and vision put forward by Bjögvinsson, Ehn, and Hillgren $(2012,102)$, we view the design of the book as more than the production of a 'thing' (i.e. an object), but rather as the design of a 'Thing' (i.e. a socio-material assembly), and we encompass the challenge of designing beyond the specific project (a move from 'projecting' to 'infrastructuring' design activities). With respect to the practical/operational aspect of how this is made possible, the process is embodied and realized through the structure of a social enterprise (Bridges).

This enables the product to maintain its freshness and relevance in parallel to the ever-evolving and progressing field of stroke medicine, care and rehabilitation, and wider technological, societal, political and cultural developments that are relevant to and position the content within a moment in time. As we have evolved in our knowledge since producing the first edition of the book, we have stepped away from the traditional rehabilitation paradigm of goal-setting and time limited improvement and from using the term 'goal'. We have moved to embodying a self-management approach without using the word 'self-management', because of the term's potential to alienate both stroke survivors and healthcare professionals. The book has provided a new common language guided by expressions of co-design contributors, for example talking about a 'thing I want to do' as opposed to a 'goal', and 'keeping going' and 'getting on with things' as opposed to 'self-managing'. This reveals a further aspect of reciprocity, as rehabilitation practitioners themselves may develop a shift in perspective on stroke and stroke rehabilitation through reading the content that was gifted by stroke survivors. This in turn allows practitioners to pass the gift on to other people with stroke by giving 
out the book, using more enabling language and valuing the benefit in seeking people's views, thus creating a multi-directional flow of information.

\section{A gift to feel supported}

The most obvious purpose of the book as a tool includes the gift of real-life experiences from people with stroke for their peers, which, from the perspective of the contributors, comes without an obligation. We learned from stroke survivors how reading about other people's stories can bring some relief to feelings of loneliness; and how reading about what others have achieved against the odds can instil a new sense of purpose and spark action about something important to the person, for example booking a holiday, starting a new hobby or seeking alternative work such as volunteering.

Additionally, the book can support practitioners and stroke survivors to work more collaboratively. Rehabilitation professionals usually introduce and hand over the book to the person with stroke, encourage its use, and jointly read, discuss, and fill in the sections of the book. Practitioners have told us that the book can spark conversations that they would not normally have. As one example, a neurosurgical nurse gave the book to a patient as a 'last-resort', because the patient was withdrawn. The patient read the book overnight, wrote down things she wanted to do in life, and told the nurse in the morning. Discovering the patient's motivation in this way, helped staff in building a relationship and engaging the patient in care and rehabilitation activities.

\section{Discussion}

In the final section of this paper, we turn to discussing our learning points from the process, which revolve around rigour, integrity, power and control. The field of design faces common critique with respect to (lack of) transparency of the process, arbitrary 
nature of decision-making and limited representativeness of evidence due to small numbers of participants. This may be regarded as a misconception by those who operate a model of knowledge production based on systematic proof and verification. In contrast, design work draws on 'abductive' reasoning, creative leaps and instinctive action; and 'designerly' ways of doing research invoke an alternative notion of rigour, heavily grounded in the theoretical sensitivity, reflexivity, integrity and experience of the design team (Cross 2001).

In accordance with the situation-specific quality of our 'research through practice' approach (Archer 1995), we established rigour in our work through reflexivity and explicit articulation of our understanding of a reciprocal relationship between codesign participants and members of the Bridges team. The nature of the infrastructure dictated that Bridges team members were closest to the thing (product) and had de facto control over it, through their roles as decision makers, their oversight and access to finances, and their relationship with and decision-making powers over production partners (e.g. external designer and printers). Nevertheless, we aimed to retain the sense of methodological core values and authenticity throughout the book. Importantly, this was supported through an awareness of the potential to 'mine' content from co-design participants in an exploitative manner, by taking their images and words to fill the pages of the book.

This leads on to the aspect of power and control, which presents a common tension during any attempt at co-designing, co-creating and co-producing. Farr (2017) describes how power and control can play out in ways that lead to 'real' co-production, where mutual alliances are forged between professionals and service users. Or conversely, co-production rhetoric of equal partnership can hide existing social inequalities and displace social justice and rights, for example as an extension of 
neoliberal market practices and the 'use' of volunteering citizens to substitute paid personnel. The most tangible manifestation of power and control in the co-design of the book was participants signing consent and release of their gifted content (interview recordings, photographs), which put the Bridges team in a position of relative control over these materials. Although there was a gift voucher given to each co-design participant in recognition of their contribution, this did not reflect fair market value of stroke survivors' time and intellectual/creative contributions. We consider that through our critical reflexive practice, by identifying various forms of reciprocity and by inviting frequent feedback and accepting veto from participants, we negotiated a positive and mutually beneficial co-design path.

We were also sensitive to creating an environment (design 'Thing'), that attempted to take account and cater to both, participants who were keen to exert more control and greater involvement during the process; and those who were comfortable giving over their image and their words, and who entrusted us with the processing of their content. This required our commitment to enabling greater engagement, and our preparedness to give over control and decision-making power to co-design participants. At the same time, it required that we were comfortable with taking content from participants and leading on processing it, if that was the participant's level of interest and engagement. This reflects a participatory design ethos, characterized by the overall mind-set that all people are creative (Kelley and Kelley 2013; Sanders et al. 2010).

Empowerment in this context can be interpreted in the sense that some people may only contribute a small aspect, or to a limited extent; but by allowing and supporting this contribution, this speaks to the democratic premise of co-design. Amiri, Wagenfeld, and Reynolds (2017), who have designed with individuals who are limited in their ability to participate, describe this as a form of advocacy. In other words, from a 
designer's perspective it can also be 'okay' to take the lead; and what makes it 'okay' is the reflexivity of the design team, and the articulation of the process, i.e. letting participants 'in' on the workings of the process and giving them choices as to the role they wish to play. This also illustrates the benefit of bringing together disciplinary domains with a common focus on the user, so that interprofessional collaboration (in our case self-management expertise from Bridges; and expertise with respect to accessibility for people with aphasia from specialist speech and language therapists at St John's Therapy Centre and Dyscover) enriches both process and product (Amiri, Wagenfeld, and Reynolds 2017).

Lastly, we acknowledge that in this piece of work there remained scope for incorporating additional co-design expertise and experience, in particular with respect to the more creative co-design techniques that utilize images and other media and materials in some form of 'making'. Described as 'collective making' (Langley, Wolstenholme, and Cooke 2018), these designer facilitated activities enable co-design participants to explore and articulate their experiences in ways that rely less on written and spoken words, which can be particularly helpful for making visible participants' tacit knowledge (as opposed to explicit knowledge). We agree with Langley, Wolstenholme, and Cooke (2018) in their assertion that many of today's challenges benefit from blending skills, knowledge and experience of trained designers with those of other stakeholders in health and social care. In the future, it is our intention to create more opportunities for co-design by stroke survivors, for example in steps 4, 5, 7 and 8 in the book development cycle, in which there was no direct involvement of people with stroke (Figure 1); and to incorporate more varied and creative co-design methods through closer collaboration with designers. We therefore view this paper as denoting a 
moment of reflexive pause, and also a stepping stone in our own learning, development and practice.

\section{Conclusion}

We have given an account of our own experiences of working with people with stroke and rehabilitation professionals to co-design a bespoke self-management resource (book). Stroke survivors gifted their stories and experiences to fill the pages of the book, which obligated us to sensitivity toward issues of power and control over content. We have demonstrated how identifying and creating the following forms of reciprocity throughout and beyond the co-design process has been critical to ensuring mutual benefit of our work: opportunities to feel listened to and help bring about positive change in healthcare; use of supportive communication strategies; placing value on the authenticity of content; increasing accessibility; and shifting practitioners' use of language and perspectives on living with stroke. Furthermore, the reciprocity loop continues as more stroke survivors and professionals use the book and provide their feedback and reflections on the design, allowing the gift to keep giving over time. 
Funding details:

This research and Stefan Tino Kulnik were supported by the National Institute for Health Research (NIHR) Collaboration for Leadership in Applied Health Research and Care South London (NIHR CLAHRC South London) at King's College Hospital NHS Foundation Trust. The views expressed in this article are those of the authors and not necessarily those of the NHS, the NIHR, or the Department of Health and Social Care.

\section{Disclosure Statement:}

Fiona Jones is founding director and CEO of Bridges Self-Management Limited, a social enterprise conducting training, research and development in self-management support in health and social care. Heide Pöstges is Director of Innovation and Training at Bridges Self-Management Limited, and Stefan Tino Kulnik is a former employee. Rosemary Townsend is CEO of Dyscover Limited, a charity offering long-term support to people with aphasia. Paul Micklethwaite declares no conflict of interest.

Data availability statement:

Not applicable.

Acknowledgements:

We are grateful to the stroke survivors and their family members who offered content for the book - their stories and experiences make the book. We also thank the stroke survivors and health professionals who contributed to the co-design in an advisory role. We thank Lucinda Hollinshead and Marilyn George for contributions to the project and helpful comments on this article. 
References

Amiri, T., Wagenfeld, A., and L. Reynolds. 2017. "User Wellbeing: An Entry Point for Collaboration Between Occupational Therapy and Design." Design for Health 1(2):187-193.

Archer, B. 1995. "The Nature of Research.” Co-design January 1995:6-13.

Bjögvinsson, E., Ehn, P., and P.-A. Hillgren. 2012. "Design Things and Design Thinking: Contemporary Participatory Design Challenges.” DesignIssues 28(3):101-116.

Cadilhac, D.A., Kilkenny, M.F., Srikanth, V., Lindley, R.I., Lalor, E., Osborne, R.H., and M. Batterbsy. 2016. "Do Cognitive, Language, or Physical Impairments Affect Participation in a Trial of Self-Management Programs for Stroke?" International Journal of Stroke 11(1):77-84.

Cross, N. 2001. "Designerly Ways of Knowing: Design Discipline Versus Design Science.” Design Issues 17(3):49-55.

van de Bovenkamp, H.M. and J. Dwarswaard. 2017. The Complexity of Shaping SelfManagement in Daily Practice. Health Expectations 20(5):952-960.

Duysburgh, P. and K. Slegers. 2015. "Reciprocity in Rapid Ethnography: Giving Back by Making the Small Things Count." Human-Computer InteractionINTERACT 2015: 292-299.

Engelter, S.T., Gostynski, M., Papa, S., Frei, M., Born, C., Ajdacic-Gross, V., Gutzwiller, F., and P.A. Lyrer. 2006. "Epidemiology of Aphasia Attributable to First Ischemic Stroke.” Stroke 37(6):1379-1384.

Farr, M. 2018. "Power Dynamics and Collaborative Mechanisms in Co-Production and Co-Design Processes." Critical Social Policy. 38(4):623-644.

Flesch, R. 1949. The Art of Readable Writing. New York: Harper \& Row.

Forster, A., Brown, L., Smith, J., House, A., Knapp, P., Wright, J.J., and J. Young. 2012. "Information Provision for Stroke Patients and Their Caregivers." Cochrane Database of Systematic Reviews 11:CD001919. doi:10.1002/14651858.CD001919.pub3.

Fricker, M. 2007. Epistemic Injustice: Power and the Ethics of Knowing. Oxford: Oxford University Press.

Holmlid, S. 2009. "Participative, Co-Operative, Emancipatory: From Participatory Design to Service Design. DeThinking Service - ReThinking Design.” Paper 
presented at the 1st Nordic Conference on Service Design and Service Innovation, Oslo, November 24-26.

Intercollegiate Stroke Working Party (ISWP). 2017. Sentinel Stroke National Audit Programme (SSNAP): Clinical Audit April 2017 - July 2017. London: Royal College of Physicians.

Intercollegiate Stroke Working Party (ISWP). 2016. National Clinical Guideline for Stroke. 5th ed. London: Royal College of Physicians.

Intercollegiate Stroke Working Party (ISWP). SSNAP Post-Acute Organisational Audit 2015: Phase 2 - Organisational Audit of Post-Acute Stroke Services Providers. London: Royal College of Physicians.

INVOLVE. 2013. Exploring the Impact of Public Involvement on the Quality of Research: Examples. Eastleigh: INVOLVE.

Jones, F., Pöstges, H., and L. Brimicombe. 2016. "Building Bridges Between Healthcare Professionals, Patients and Families: A Coproduced and Integrated Approach to Self-Management Support in Stroke." NeuroRehabilitation 39(4):471-480.

Jones, F., Riazi, A., and M. Norris. 2013. "Self-Management after Stroke: Time for Some More Questions?” Disability and Rehabilitation 35(3):257-264.

Jones, F. 2006. "Strategies to Enhance Chronic Disease Self-Management: How Can We Apply This to Stroke?” Disability and Rehabilitation 28(13-14):841-847.

Jones, F. 2004. “An Individual Approach to Stroke Recovery.” Physiotherapy Research International 9(3):147-148.

Kelley, D., and T. Kelley. 2013. Creative Confidence. Unleashing the Creative Potential Within Us All. New York: Crown Business.

Kincaid, J.P., Fishburne, Jr., Robert, P., Rogers, R.L., and B.S. Chissom. 1975. Derivation of New Readability Formulas (Automated Readability Index, Fog Count and Flesch Reading Ease Formula) for Navy Enlisted Personnel. Millington, TN: Naval Technical Training Command Millington TN Research Branch.

Langley, J., Wolstenholme, D., and J. Cooke. 2018. “'Collective making’ as knowledge mobilisation: the contribution of participatory design in the co-creation of knowledge in healthcare." BMC Health Services Research 18:585.

Mauss, M. 2000. The Gift: The Form and Reason for Exchange in Archaic Societies. New York: W.W. Norton \& Company. 
McCleland, I., and J. Fulton Suri. 2005. "Involving People in Design.” Chap. 11 in Evaluation of Human Work, edited by Wilson J.R., and N. Corlett, 281-334. 3rd ed. Boca Raton: CRC Press.

National Institute for Health and Care Excellence (NICE). 2013. Stroke Rehabilitation in Adults. Clinical Guideline 162. London: National Institute for Health and Care Excellence.

National Institute for Health Research (NIHR) Clinical Research Network (CRN) Stroke. 2014. Engaging People Who Have Aphasia. A Set of Resources for Stroke Researchers. London: National Institute for Health Research (NIHR) Clinical Research Network (CRN) Stroke.

Pearl, G., and M. Cruice. 2017. "Facilitating the Involvement of People with Aphasia in Stroke Research by Developing Communicatively Accessible Research Resources." Topics in Language Disorders 37(1):67-84.

Rose, T., Worrall, L.E., Hickson, L.M., and T.C. Hoffmann. 2012. "Guiding Principles for Printed Education Materials: Design Preferences of People with Aphasia." International Journal of Speech-Language Pathology 14(1):11-23.

Rose, T.A., Worrall, L.E., Hickson, L.M., and T.C. Hoffmann. 2011. “Aphasia Friendly Written Health Information: Content and Design Characteristics.” International Journal of Speech-Language Pathology 13(4):335-347.

Sanders, L., and P.J. Stappers. 2014. "From Designing to Co-Designing to Collective Dreaming: Three Slices in Time.” Interactions Nov-Dec:24-33.

Sanders, E.B.N., Brandt, E., and T. Binder. 2010. "A framework for organizing the tools and techniques of participatory design." Paper presented at the 11th Biennial Participatory Design Conference, Sydney, November 29 - December 03.

Social Care Institute for Excellence (SCIE). 2015. SCIE Guide 51: Co-Production in Social Care: What It Is and How to Do It. London: Social Care Institute for Excellence.

Star, S.L. 2010. "This Is Not a Boundary Object: Reflections on the Origin of a Concept." Science, Technology, \& Human Values 35(5):601-617.

Star, S.L. and J.R. Griesemer. 1989. "Institutional Ecology, 'Translations' and Boundary Objects: Amateurs and Professionals in Berkeley's Museum of Vertebrate Zoology, 1907-39.” Social Studies of Science 19(3):387-420. 
World Health Organization (WHO). 2015. WHO Global Strategy on People-Centred and Integrated Health Services: Interim Report. Geneva: World Health Organization.

World Health Organization (WHO). 2013. Health Literacy. The Solid Facts. Geneva: World Health Organization.

Worrall, L., Rose, T., Howe, T., McKenna, K., and L. Hickson. 2007. "Developing an Evidence-Base for Accessibility for People with Aphasia." Aphasiology 21(1):124-136.

Wray, F., Clarke, D., and A. Forster. 2017. "Post-Stroke Self-Management Interventions: A Systematic Review of Effectiveness and Investigation of the Inclusion of Stroke Survivors with Aphasia.” Disability and Rehabilitation 40(11):1237-1251. 


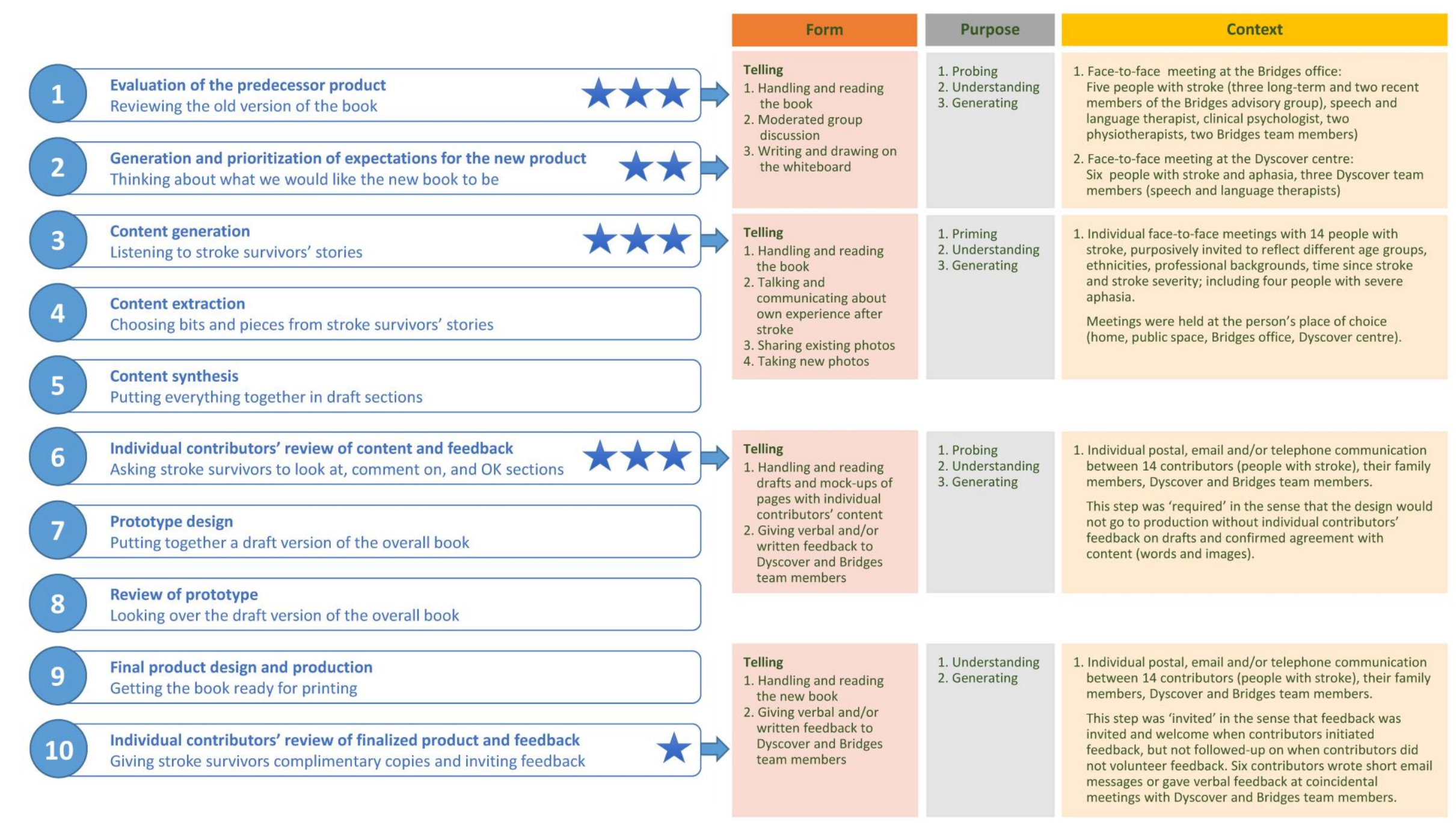


Figure 1. Sequential steps in the book development cycle. Level of collaboration is indicated from zero stars (no direct involvement of people with stroke) to three stars (ownership and control by people with stroke). Co-design activities are described according to the categorisation of tools and techniques proposed by Sanders, Brandt and Binder (2010), i.e. with respect to form, purpose and context. Form (kind of action) includes making, telling and/or enacting. Purpose (aim of action) includes probing, priming, understanding and/or generating. Dimensions of context are group size and composition, face-to-face $v s$. online, venue, and stakeholder relationships. 
(a)
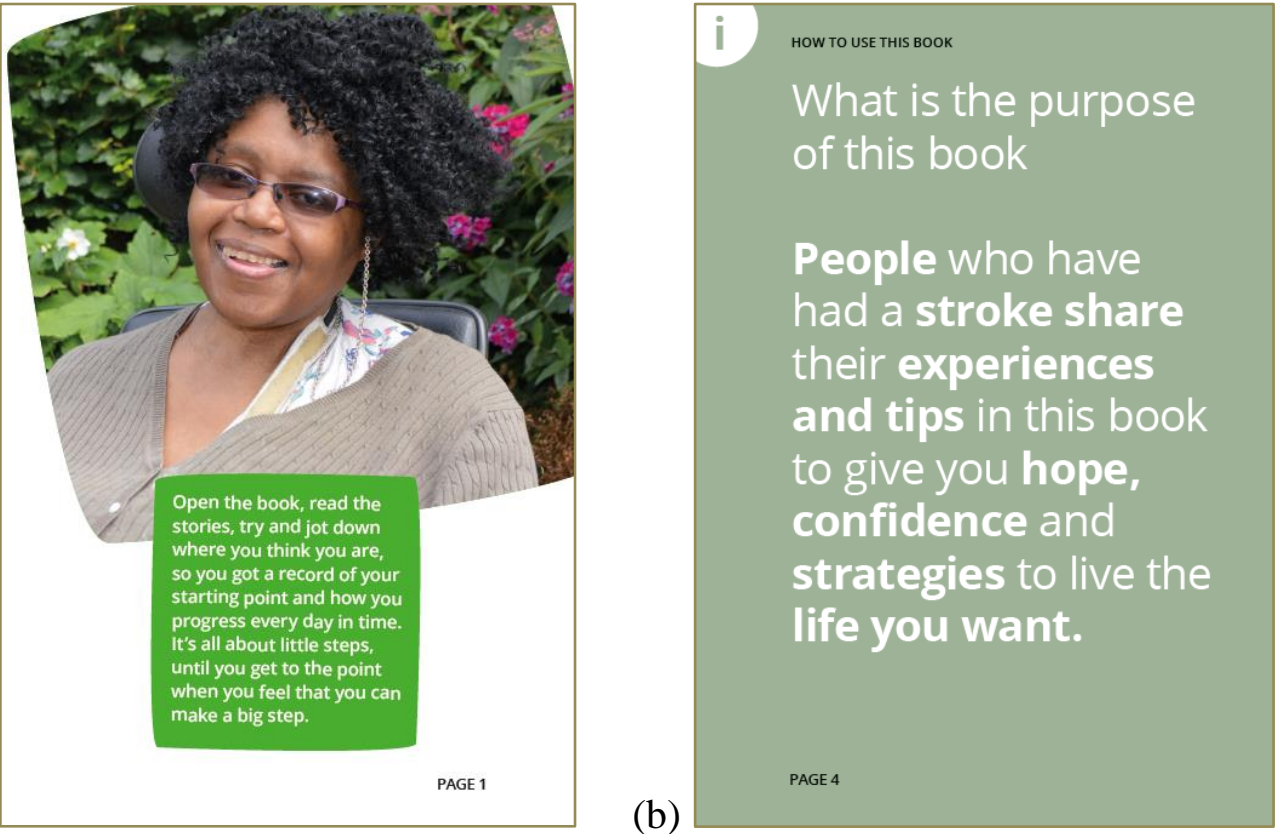

Figure 2. Pages introducing the reader to the purpose of the book, using (a) the words of Eileen, one of the stroke survivors who contributed to the book, and (b) a passage authored by the Bridges team.
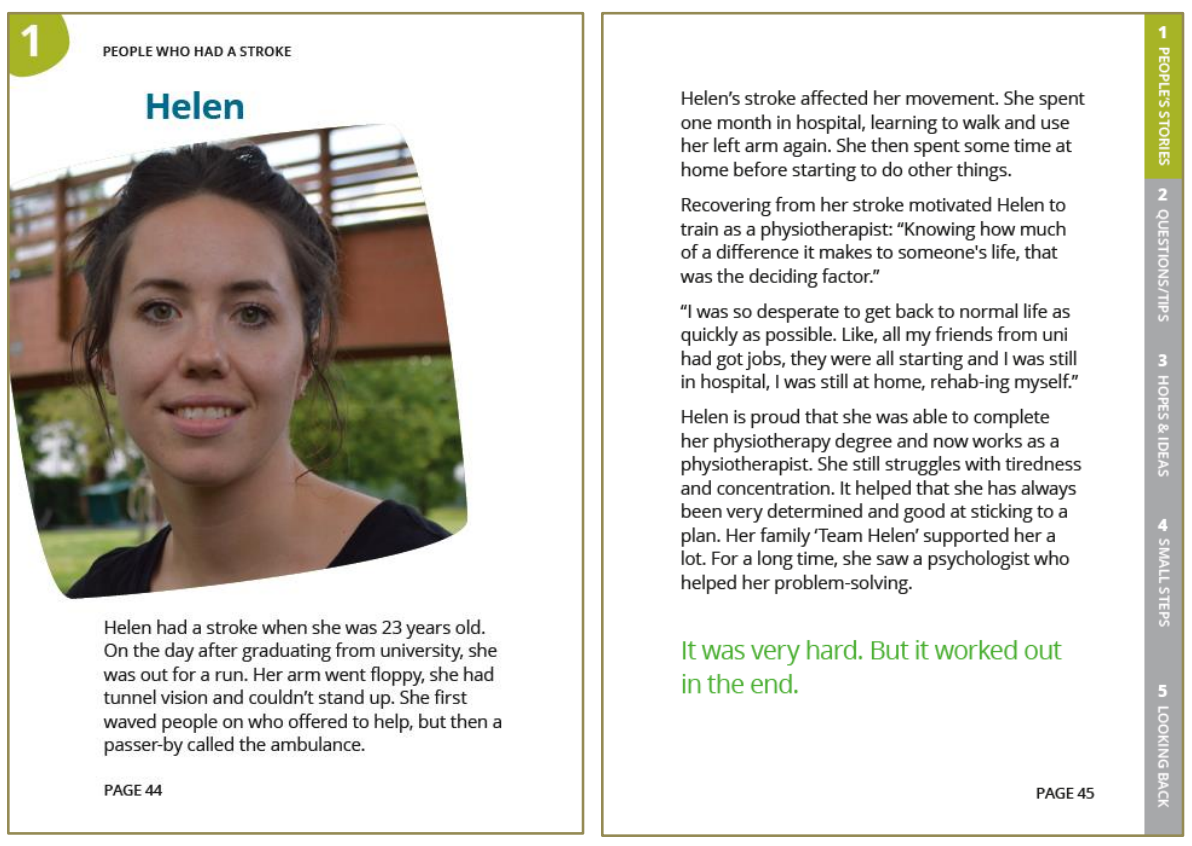

Figure 3. Pages introducing Helen, one of the people who share their stories and experiences in the book. 

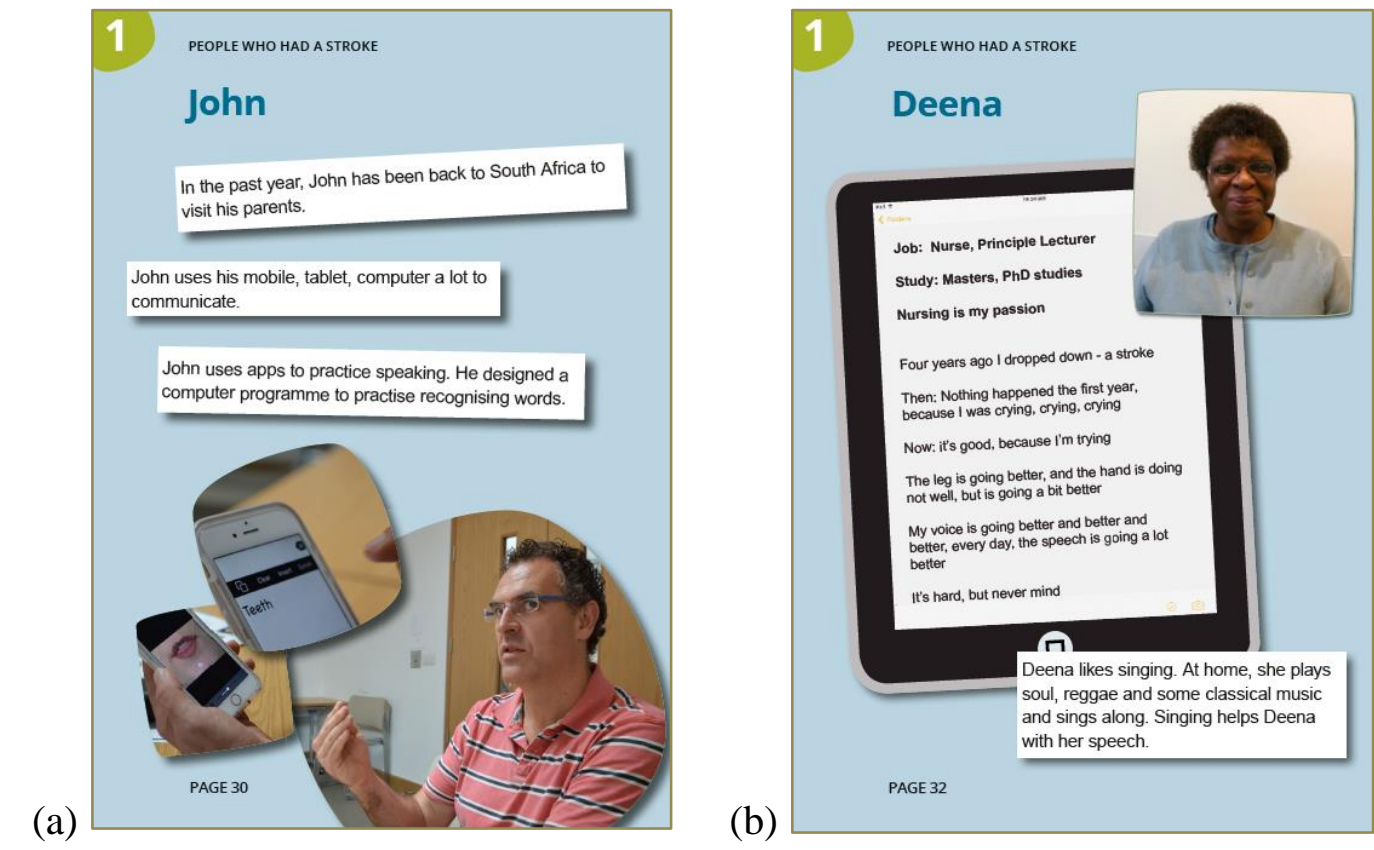

Figure 4. Pages introducing (a) John and (b) Deena, two of the people with severe aphasia who share their stories and experiences in the book. 
What will I have to do?

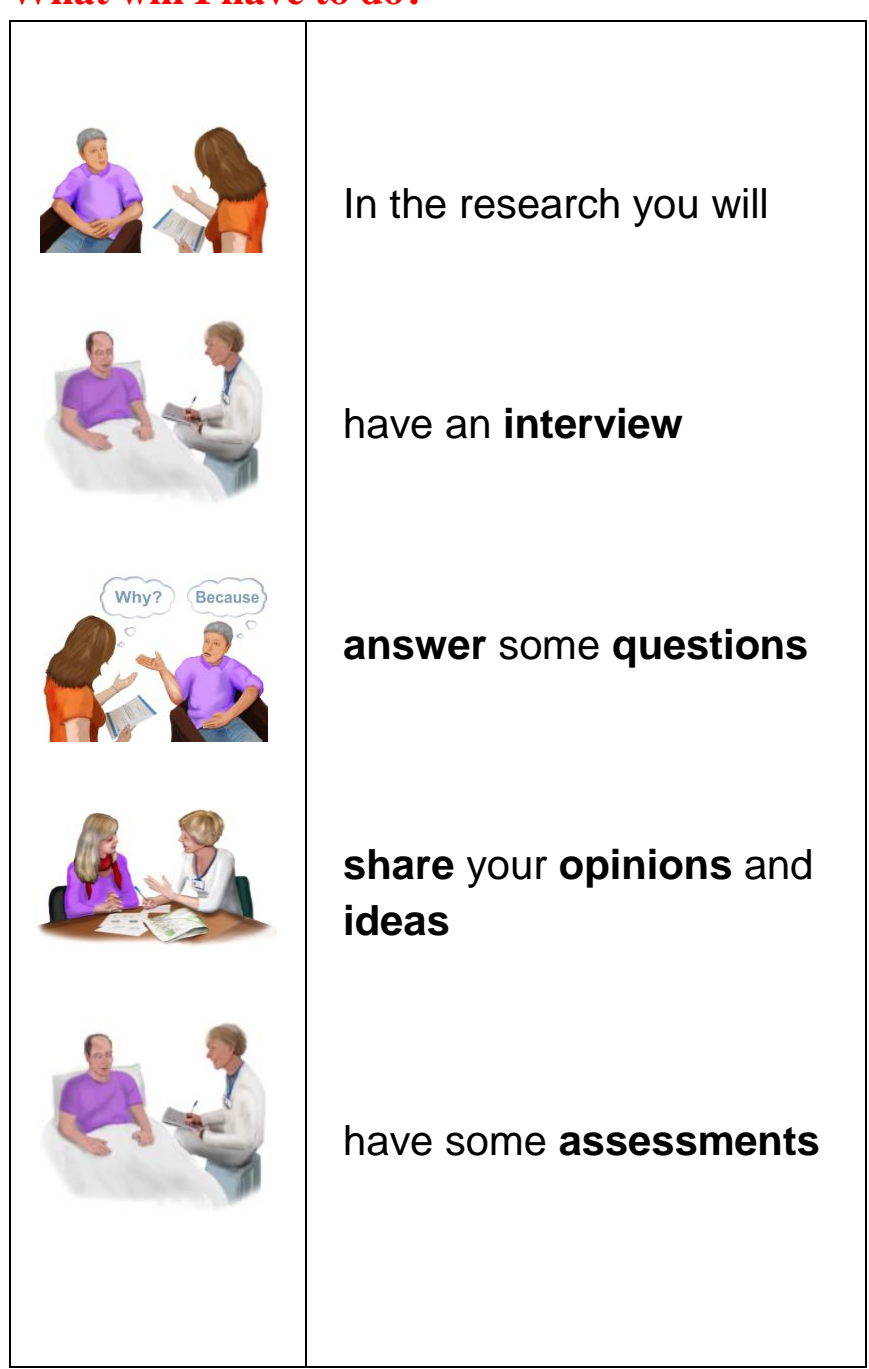

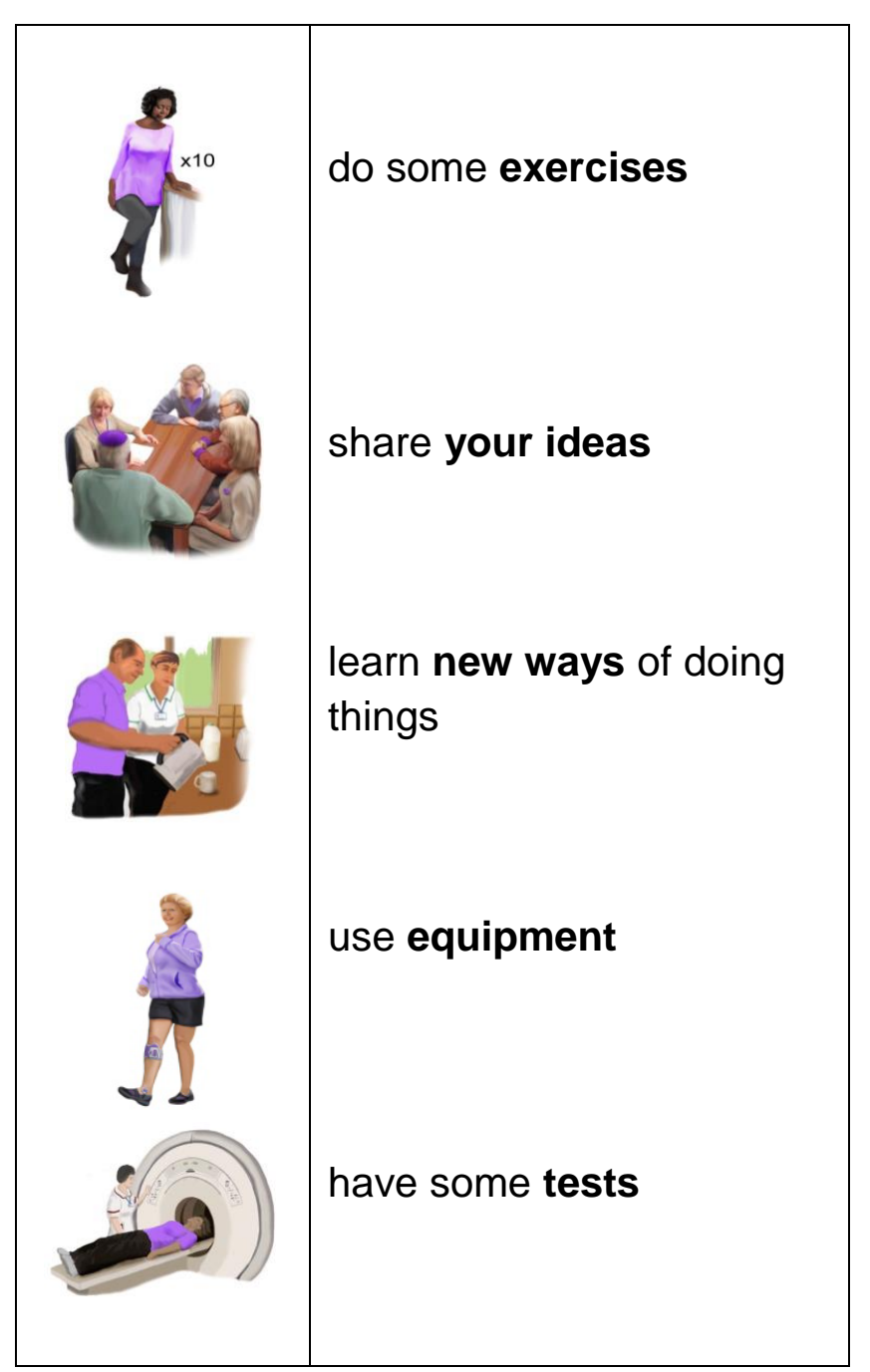


Figure 5. Example of a design format for written/printed research-related materials that are accessible to people with aphasia. Reproduced with permission from NIHR CRN Stroke (2014). 